\title{
Reformas do Estado e da educação: o caso das escolas profissionais em Portugal*
}

\author{
Fátima Antunes \\ Universidade do Minho, Instituto de Educação e Psicologia
}

\section{Introdução}

A criação do subsistema de escolas profissionais em Portugal, em 1989, constitui uma medida de política educativa que condensa um conjunto importante de tendências marcantes no terreno da educação. Em outros trabalhos, sublinhámos que essa inovação se integrou numa fase de intensificação da dinâmica, em curso desde os anos de 1970, de europeização e de construção de um referencial global europeu para as políticas educativas nacionais, encontrando-se associada a uma modalidade específica de produção desse processo de europeização que consistiu na recontextualização de políticas comunitárias. Assim, essa medida de política educativa expressa uma agenda globalmente estruturada para a educação e evidencia o modo como a União Europeia se constitui como uma instância supranacional que medeia, veicula e modela pressões, constrangimentos e orientações de inscrição global (Antunes, 2000, 2001, 2004).

\footnotetext{
* Foi conservada a ortografia portuguesa.
}

A perspectiva de uma agenda globalmente estruturada para a educação admite, com base em estudos de economia política, que os Estados-nação se confrontem com "um conjunto sistemático de questões", colocadas quer pelos processos de globalização (económicos, políticos, culturais) quer pela situação desses mesmos Estados no contexto internacional que condiciona a sua relação com aqueles processos (Dale, 2000 , p. 428). O argumento principal dessa perspectiva para a educação é sustentado pela análise de que o modo como aqueles problemas se apresentam e a prioridade relativa que lhes é atribuída são crescentemente modelados pelos constrangimentos e pressões de relações globais (sobretudo económico-políticas), dispondo os Estados de um leque diminuído de opções quanto à orientação das suas políticas. Tal não implica que a actuação do Estado seja determinada pelo contexto económico-político global/regional, mas as orientações adoptadas e os processos sociais implementados serão o resultado da interacção complexa entre a percepção/interpretação e formulação daqueles problemas pelos actores do Estado, da sociedade civil e da economia, e o leque de respostas e soluções 
disponibilizáveis por meio das instituições existentes ou possíveis a partir dos recursos políticos, económicos e culturais mobilizáveis no contexto nacional.

O complexo de dinâmicas, instituições, processos e relações sociais que alguns de nós, na senda de Wallerstein, procuraram compreender mobilizando o conceito de moderno sistema-mundo capitalista sofre, desde há algumas décadas, transformações dramáticas que têm vindo a ser teorizadas como configurando processos de globalização. Essas mudanças são, por alguns autores, referidas como globalizações para sublinhar a heterogeneidade, as assimetrias, contradições e desequilíbrios que marcam as constelações de relações sociais que as corporizam (Giddens, 2000; Santos, 2001); as dinâmicas que enunciamos são hoje vividas na economia, na esfera política ou no universo cultural por meio de uma combinatória de processos cuja instabilidade não permite ainda apreender qualquer configuração identificável como constituindo um novo regime de acumulação (Boyer, 1994).

Neste texto, discutiremos outras vertentes daquela inovação, para além daquelas enunciadas, também significativamente relacionadas com dinâmicas de globalização. Mais concretamente, defenderemos que a intensificação de relações de escala global, que ocorre de modo heterogéneo, arrítmico e assimétrico nos domínios económico, político e cultural, tem um impacto assinalável no domínio da educação, nomeadamente através da gestação de um novo modo de regulação. ${ }^{1}$ Este processo de edificação de articulações e instituições emergentes assume uma expressão particularmente viva no nível de transformações sofridas pelo Estado, nomeadamente as que se rela-

${ }^{1}$ Esse conceito, desenvolvido pela Escola da Regulação francesa, releva que a trama de instituições que favorecem a congruência dos comportamentos individuais e coletivos e medeiam os conflitos sociais chega a produzir as condições para a estabilização (sempre temporária e dinâmica, ainda que prolongada) de um dado regime de acumulação (Boyer, 1987, p. 54-55, 1994, p. 3; Aglietta, 1997, p. 412 e 429; Antunes, 1998, p. 30-32). cionam com formas de actuação que se distanciam daquelas que tipicamente caracterizavam a forma política do Estado de bem-estar. Com base no trabalho de vários investigadores, condensamos este vasto leque de modalidades de intervenção pública sob as noções de Estado de competição, Estado em rede e Estado articulador, que, embora de modo imperfeito e insatisfatório, pretendem dar conta de formas específicas de acção estatal que podem surgir singularizadas ou combinadas em determinadas áreas da vida social. O Estado parece assim envolvido em transformações que apontam para três configurações ou formas de actuação parciais fundamentais: o Estado de competição (competition state), cujas prioridades se orientam para a actuação em instâncias supranacionais e para a intervenção no nível nacional de modo a promover a competitividade da sua economia e a expandir as oportunidades de acumulação (Cerny, 1990, p. 53, 205, 220ss); o Estado em rede (network state), enquanto articulação de segmentos de Estados que asseguram a intervenção em áreas da vida social cujo controlo escapa às fronteiras da soberania nacional (Castells, 1997, p. 266269, 1998, p. 331, 350-352, 366-367, 375); e o Estado articulador, voltado para a criação de condições de mediação dos interesses sociais, sob novas fórmulas e arranjos institucionais de que não é o único nem o principal protagonista (Santos, 1998, p. 5969, 1999, p. 38-39). ${ }^{2}$

A criação e o desenvolvimento do subsistema de escolas profissionais em Portugal representou a edificação de novas instituições e processos educativos que envolveram a conjugação das formas de actuação como Estado de competição e Estado articulador, que se traduzem por uma redefinição dos serviços educativos (e de bem-estar) e do papel do Estado na sua governação.

${ }^{2}$ Para uma discussão mais aprofundada dessa problemática, consultar Antunes (2004, p. 81-88). Afonso (2001) analisa algumas importantes implicações da redefinição do papel do Estado para as políticas educativas. 


\section{As escolas profissionais e a emergência de novas formas de governação da educação}

\author{
Novas combinações institucionais: \\ o Estado, o mercado e o terceiro sector
}

As escolas profissionais constituem uma inovação que entra em ruptura com o modo como a educação escolar fora proporcionada em Portugal até ao momento, no que toca a qualquer das actividades financiamento, fornecimento e regulação -, cuja análise Roger Dale considera incontornável para compreender a governação (governance) da educação (Dale, 1994, p. 2-6, 1997). ${ }^{3}$ A proposta pretende tornar possível a identificação, em cada momento e situação, da combinação institucional ("institutional mix") implementada em relação a determinados serviços, actividade ou área das políticas públicas e sociais. A consideração daquele conjunto de aspectos da governação permite especificar e aprofundar a análise de políticas, modalidades e tendências em formação ou em acção no campo da organização e actuação do Estado e do bem-estar social. Seguindo ainda Roger Dale, consideraremos, para cada uma das áreas mencionadas (financiamento, fornecimento e regulação), que tais actividades podem ter lugar por meio do Estado, do mercado ou do comummente designado terceiro sector ou ainda de modalidades que conjugam várias dessas formas institucionais.

${ }^{3}$ Essa análise do(s) modelo(s) de governação do subsistema de escolas profissionais ao longo dos seus já quinze anos de funcionamento incidirá mais demoradamente no período compreendido entre 1989 e 1998. Na sequência de perturbações e instabilidades diversas, no que respeita ao financiamento dessas escolas, foi realizada, em 1996, uma avaliação do sistema de escolas profissionais (Silva, Silva \& Fonseca, 1997) e posteriormente estabelecido um novo "regime de criação, organização e funcionamento de escolas e cursos profissionais no âmbito do ensino não-superior" por meio do decreto-lei n ${ }^{\circ}$ 4/98 de 8 de janeiro. Esse diploma introduziu alterações diversas cujos significados e consequências também afloraremos.
Nessa perspectiva, torna-se possível realçar e constituir como significativos um conjunto de elementos característicos do subsistema de escolas profissionais, aprofundando a compreensão do sentido potencial da sua concepção e implementação. Assim, o seu financiamento é fundamentalmente público e estatal (incluindo aquele que provém dos Fundos Estruturais da União Europeia), contemplando também a participação das entidades promotoras e dos estudantes, através de propinas, entre outras modalidades; dessa forma, embora fortemente sustentado pelo Estado, apresenta ainda assim um carácter misto que não deve ser ignorado: de salientar que essa estrutura de financiamento, que se mantém durante cerca de uma década, deveria, segundo o projecto dos seus criadores políticos, ter progressivamente evoluído para a auto-sustentação das escolas, através do investimento dos promotores e de receitas provenientes quer das propinas dos alunos, quer das empresas interessadas nas formações proporcionadas, quer aquelas geradas pelas próprias instituições (Azevedo, 1991, p. 156, 168; Alves, 1996, p. 38-41).

O fornecimento do serviço educativo foi assumido pelas escolas profissionais, instituições dotadas de autonomia, com base num contrato-programa com o Estado, que especificava responsabilidades, competências e âmbitos de actuação. As áreas da relação com os produtores (professores, formadores e funcionários) e beneficiários (alunos) do serviço foi, desse modo, deslocada para o nível da instituição local; no entanto, se o estatuto dos produtores e beneficiários releva duma relação individualizada, parcialmente mercadorizada (isto é, sujeita à capacidade e condições de negociação da relação laboral para uns e, pese embora o carácter específico de que tal se reveste, de aquisição do serviço para outros), aquele é também fortemente determinado por normas oriundas dos poderes públicos (quer estatais, quer da União Europeia) relativas à prestação do serviço (perfil e qualificações dos formadores ou custo/valor atribuído ao tempo de formação), bem como às características dos seus destinatários (qualificações, faixa etária, entre outras). 
A regulação do serviço educativo é protagonizada basicamente por duas entidades: a administração do sistema educativo e as escolas. ${ }^{4}$ A primeira entidade assume a definição das normas e critérios genéricos e essenciais relativos à oferta de cursos (que necessitam de aprovação prévia para poderem funcionar), aos currículos e planos de estudos, à avaliação e à gestão das escolas. As próprias escolas (leia-se os seus órgãos de direcção) concebem e propõem para aprovação os seus projectos de ensino, ficando a gestão curricular e pedagógica, financeira e administrativa como competências do seu foro próprio (ver Quadro 1).

Obtemos assim um quadro (inspirado em Dale, 1994, p. 5, 1997) que orienta a análise no sentido de que a criação das escolas profissionais instituiu uma política ambígua, híbrida e compósita que não conduziu nem à diminuição do papel do Estado na go-

\section{Quadro 1}

A governação das escolas profissionais entre 1989 e 1998

\begin{tabular}{|c|c|c|}
\hline & Governação & $\begin{array}{l}\text { Formas intitucionais } \\
\text { de coordenação social }\end{array}$ \\
\hline Financiamento & \begin{tabular}{|c} 
Estado/UE \\
entidades promotoras \\
beneficiários/consumidores
\end{tabular} & $\begin{array}{c}\text { Estado } \\
\text { Terceiro Sector } \\
\text { Mercado }\end{array}$ \\
\hline Fornecimento & Escolas & $\begin{array}{c}\text { Terceiro Sector? } \\
\text { Mercado? }\end{array}$ \\
\hline Regulação & $\begin{array}{l}\text { Estado (administração } \\
\text { do sistema educativo) } \\
\text { Escolas (órgãos de } \\
\text { direcção e gestão) }\end{array}$ & $\begin{array}{c}\text { Estado } \\
\text { Terceiro Sector }\end{array}$ \\
\hline
\end{tabular}

${ }^{4}$ Para Roger Dale, regulação designa, nesse contexto, as actividades de controlo, isto é, de definição do enquadramento para o fornecimento dos serviços educativos que o Estado assume através de políticas e sanções legais (Dale, 1997, p. 277). Parecendo consistir numa atribuição última daquele, é possível, no entanto, admitir que outras instâncias ou entidades desempenhem igualmente um papel em áreas definidas pelo, e porventura por delegação do, Estado. vernação dos serviços educativos proporcionados, e muito menos à assunção exclusiva dessas actividades por qualquer das outras formas institucionais de coordenação social. ${ }^{5}$ Pelo contrário, o Estado surge ainda como principal financiador e regulador, com os mecanismos de mercado e as instituições e modalidades de organização e actuação eventualmente referenciáveis ao terceiro sector participando também dessas áreas de governação. ${ }^{6} \mathrm{O}$ fornecimento (isto é, a pro-

${ }^{5}$ Como foi assinalado por um autor analisando as políticas educativas desenvolvidas nesse período: “o Estado teve um papel extremamente relevante e decisivo na génese e desenvolvimento das escolas profissionais, não se limitando a apoiar ou reconhecer o papel (autónomo) da sociedade civil. É isto, entre outras dimensões, que faz da emergência das escolas profissionais mais um exemplo da especificidade das políticas neoliberais em Portugal: trata-se, mais propriamente, de uma política educacional híbrida" (Afonso, 1998, p. 227).

${ }^{6} \mathrm{~A}$ alocação das entidades promotoras e das escolas aos domínios do mercado como do terceiro sector deriva da conjugação de duas condições explícitas no modelo de criação e funcionamento das escolas profissionais: (i) por um lado, podiam ser promotores um conjunto de entidades públicas e privadas (autarquias, cooperativas, empresas, sindicatos, associações, fundações, instituições de solidariedade social, organismos públicos) cuja vocação (e modos de operação característicos) remetem, na maior parte dos casos, para o domínio do terceiro sector, mas também para a esfera do mercado; (ii) por outro lado, o financiamento previsto (pelas entidades promotoras, beneficiários, receitas públicas, prestação de serviços etc.) tornava hipoteticamente possível a emergência de qualquer combinação institucional conducente à definição das escolas profissionais como entidades situadas no domínio do mercado ou do terceiro sector quer no que toca à sua finalidade não-lucrativa, quer no que toca à importância dos mecanismos de mercado para o seu funcionamento (decreto-lei n ${ }^{\circ}$ 26/89 de 21 de janeiro, particularmente artigos $5^{\circ}$ - promotores, 16 - gestão, 17 receitas e 20 - bolsas). Os dados relativos à concretização da política, nos primeiros anos, sugerem que as entidades promotoras tendem a situar-se expressivamente no domínio do Estado e do terceiro sector (Alves, 1996, p. 43). No que toca às escolas, as dificuldades conhecidas quanto à sua sustentação financeira sugerem, 
dução e distribuição) de serviços educativos aparece como responsabilidade exclusiva das escolas, enquanto instituições autónomas e, na sua maioria, privadas, cujo traço característico predominante parece ser a hibridez, pelo facto de, por um lado, se verificar a ausência de carácter lucrativo (terceiro sector) e, por outro, a presença insofismável de lógicas de mercadorização no que toca quer à produção quer à distribuição dos serviços educativos. ${ }^{7}$

As escolas profissionais constituíram assim uma tentativa para implementar novos modos de governação, num terreno em que o Estado se constituíra até ao momento como principal protagonista em cada uma das dimensões assinaladas, por meio da instabilização e rarefacção de fronteiras entre o domínio público, estatal e não-estatal, e o domínio privado, referenciável ao mercado mas também a formas institucionais não-lucrativas (terceiro sector). Tornava-se, ainda hipoteticamente, possível caminhar para um eventual protagonismo crescente quer dos beneficiários quer dos consumidores finais, nomeadamente por intermédio de mecanismos de liberalização baseados na procura, incluindo ou não dinâmicas fortes de concorrência entre escolas.

Novas combinações institucionais: o contrato-programa, os promotores e o partenariado

O lançamento do subsistema de escolas profissionais foi realizado através da institucionalização de

entre outras explicações, que o seu carácter não-lucrativo é um facto e que os mecanismos de mercado passíveis de serem accionados (propinas pagas pelos beneficiários, bolsas atribuídas por entidades interessadas ou financiamentos privados, nomeadamente empresas) não são suficientemente importantes para as viabilizar do ponto de vista económico.

${ }^{7} \mathrm{O}$ carácter não-lucrativo das escolas, não sendo formalmente estabelecido pelo articulado do decreto-lei que as institui, é explicitamente afirmado no normativo que, em 1993, alterou e substituiu aquele (decreto-lei ${ }^{\circ} 70 / 93$ de 10 de março, art. $2^{\circ}$, ponto 1 ). três figuras que conjuntamente expressam e viabilizam as alterações introduzidas e potenciadas ao nível da governação da educação: o contrato-programa, os promotores e o partenariado.

Definindo a política e o modelo institucional, financiando a maior parte dos custos de funcionamento, regulando a distribuição geográfica e por áreas de formação, prescrevendo a estrutura curricular e fixando os parâmetros de variação da mesma, indicando as modalidades de criação e o tipo de gestão (privada) das escolas, o Estado, como se procurou mostrar, capacitou e encorajou a emergência de uma nova combinação institucional. Através do contrato-programa era criada uma entidade, geralmente de natureza privada, a quem o Estado reconhecia um conjunto de poderes e competências e atribuía um leque de responsabilidades relacionados com a oferta de cursos profissionais em nível local. Tal entidade surgia com base numa proposta apresentada por promotores localmente sediados, que, com o Estado, assumiam legalmente a já referida divisão de responsabilidades.

A consequência mais importante dessa divisão de responsabilidades parece ser a individualização e a privatização da relação entre a instituição e o serviço educativo e os produtores e beneficiários desse serviço. Quanto aos produtores, tal verifica-se por força do contrato (individual) de trabalho a que estão obrigados, que também flexibiliza (isto é, precariza) as relações laborais na esfera da educação. Por exemplo, em duas escolas que estudámos verifica-se, no que respeita à situação profissional e regime de trabalho dos seus assalariados, uma situação em que prevalece a tendência para a precarização e individualização dos contratos e vínculos laborais, sobretudo em relação ao corpo docente. Para essa categoria de trabalhadores a norma é, na verdade, o estabelecimento de uma relação salarial que rompe com o modelo em vigor no ensino público e com a noção de escola como um local de trabalho tendencial e desejavelmente estável e exigente da dedicação exclusiva dos profissionais de ensino. Não constituindo, como se sabe, uma excepção - já que essas situações têm vindo a multiplicar-se sobretudo 
nos subsistemas onde a dimensão do sector privado se ampliou significativamente nas duas últimas décadas (por exemplo, o ensino superior ou a educação pré-escolar) -, as escolas profissionais configuram mesmo assim um caso único, por se tratar de todo um subsistema de ensino que assenta em contratos de trabalho precários, individualizados, sem dedicação exclusiva, e de que está completamente ausente a noção de carreira dos seus profissionais.

Quanto aos beneficiários, a sua participação numa escola profissional passa pela escolha de uma instituição e serviço educativos com os quais mantêm uma relação individual de provisão-aquisição, bem simbolizada, do nosso ponto de vista, pela figura do contrato pedagógico formalmente estabelecido, bem como pela existência de propinas.

Numa análise sobre a privatização da educação, Carlos Estevão defende que

\footnotetext{
[...] na sequência da nova ideologia no campo da educação - cujos traços mais significativos poderíamos resumir à generalização da regulação do mercado educativo, à transformação do cidadão em consumidor com direito a escolher a escola da sua preferência, à reindividualização das relações sociais, à ênfase na capacidade empreendedora e criativa dos atores educativos e à promoção do consumidor em modelo cívico - a retirada do Estado do funcionamento da educação é reivindicada. (Estevão, 1998b, p. 118)
}

Fica ainda estabelecido um nível de responsabilidade intermédio entre os cidadãos e a autoridade política legítima que controla e avaliza o serviço proporcionado. Doravante, a responsabilidade imediata face aos beneficiários (e produtores) é assumida pela entidade que fornece o serviço - a escola. A autoridade política em matéria de educação retém o poder e a competência de definir e regular o tipo de serviço, o modo como é fornecido, o conteúdo do mesmo (em grande parte), declinando, no entanto, a responsabilidade directa e imediata pelo modo como tal serviço é prestado, e pelos seus resultados em cada situação concreta e específica e na relação com os seus beneficiários e produtores.
Uma outra ruptura se pode vislumbrar num tal projecto. A administração da educação ocorrera até então, no contexto do sistema regular de ensino, através de um modelo centralizado em que a direcção (e as funções expressivas de definição de políticas) se concentra nos órgãos de topo do sistema, e a execução (e funções técnicas de gestão) são alocadas aos diferentes órgãos das escolas e genericamente protagonizadas pelos professores (Lima, 1992, p. 255-272). O modelo institucional criado para as escolas profissionais, ao deslocar o fornecimento para a esfera de instituições (geralmente) privadas e locais, conferindo-lhes autonomia administrativa, financeira e pedagógica, alterou aquela distribuição de poderes. Se as funções mais expressivas de direcção permaneceram em parte da competência dos órgãos da administração central, enquanto alguns poderes foram redistribuídos para a esfera de entidades locais (definir a estrutura organizativa da escola, o modo de designação e composição dos seus órgãos), quer professores, quer funcionários, quer alunos parecem ter sido os grandes ignorados nessa alocação de poderes.

Ao criar um subsistema em que as escolas são geralmente privadas, ao atribuir às entidades promotoras a definição das modalidades de exercício da autonomia, dispensando-se de garantir um qualquer estatuto particular aos produtores e beneficiários directos do serviço educativo (professores, funcionários, alunos), o Estado criou um modelo institucional que deliberadamente rompia com o modelo de administração e organização das escolas no sistema regular de ensino, em particular com o estatuto que era conferido aos professores. Daí que, no modelo institucional das escolas profissionais, a abrangência e diluição do perfil das entidades promotoras, enquanto um razoável protagonismo lhes é concedido na organização das escolas e na configuração do exercício da autonomia conferida, poderá encontrar explicação nas conseqüências que daí advêm, por um lado, para a viabilização do projecto estatal de fundação de uma nova modalidade de provisão da educação e, por outro lado, na redistribuição de poderes entre os diferentes protagonistas da administração da educação: aos professores, 
encarregados de educação, alunos e funcionários é retirada qualquer possibilidade de participação na definição do modelo de organização de escolas que, sendo privadas, são fundadas pelo Estado.

O partenariado socioeducativo que fundou as escolas profissionais era baseado num contrato-programa, que simultaneamente criava uma instituição geralmente privada produtora de serviços educativos e regulava a sua relação contratual com o Estado. Nessa medida, pode ser entendido como a tentativa voluntarista deste para, num primeiro momento, fortalecer as condições para, e estimular:

a) por um lado, o estabelecimento de um sector juridicamente privado no âmbito do ensino profissional;

b) por outro lado, a alteração das formas institucionais de regulação das relações dos beneficiários com a educação, redefinindo os serviços educativos como objecto de relações concorrenciais e mercadorizadas.

A figura do contrato-programa, mais tarde codificada como configurando uma fórmula partenarial, é o instrumento que permite a iniciativa e o envolvimento do Estado na criação de instituições privadas, mas também o seu apoio decisivo ao estabelecimento de um sector privado de ensino orientado para fundar um mercado concorrencial de serviços educativos. $\mathrm{Na}$ verdade, o empenho voluntarista de agentes e agências do Estado na promoção de "nichos" de investimento e de oferta privados no ensino profissional e no encorajamento de relações concorrenciais e de mercadorização no seio da educação parece ter-se diluído à medida que a implantação das escolas revelava serem diminutas as possibilidades de enraizamento e consolidação de tais projectos com base quer na acção de agentes privados capazes de e interessados em, custear a oferta, quer nas condições dos beneficiários para participar significativamente no financiamento das instituições. Assim, esse vector do projecto e do modelo obteve uma expressão (quase) residual, gerando uma situação paradoxal de um subsistema de ensino promovido pelo Estado, publicamente financiado a quase cem por cento, e constituído por escolas cujos titulares são entidades privadas, na sua esmagadora maioria compostas por órgãos da administração local e por instituições associáveis a, ou funcionando como, organizações do designado terceiro sector.

A tónica nas dimensões de privatização, de promoção da concorrência e de mercadorização dos serviços educativos vai desaparecendo à medida que as dimensões partenariais são crescentemente enaltecidas e que o modelo institucional vai assumindo o carácter de "inovação protegida", em absoluto contraste com o discurso agressivo da "natureza empresarial, flexível e ágil" e da sobrevivência das escolas pela independência diante do Estado (Correio Pedagógico, 1988; Azevedo, 1991, p. 156).

\section{Na senda de um quase-mercado}

A interpretação dos dados apresentados sugere a hipótese de que a configuração desse subsistema criou, desde o primeiro momento, condições para a constituição de um quase-mercado. ${ }^{8}$ Os quase-mercados de bem-estar caracterizam-se pela retirada do Estado da área do fornecimento de serviços e a sua substituição por entidades independentes (lucrativas ou não) que competem por clientes e/ou por contratos públicos; o Estado torna-se (ou cria) geralmente a agência que adquire os serviços em representação dos beneficiários (Le Grand \& Bartlett, 1993, p. 3 e 10).

A separação e a alocação das diversas atividades de governação verificadas no caso das escolas profissionais parecem sugerir que a combinação institucional que caracteriza o subsistema é congruente com (ou potencia) aquela modalidade de organização da provisão de bem-estar social. No entanto, os dados

${ }^{8}$ Para uma análise desenvolvida da formação de quasemercados de bem-estar, sobretudo a partir da década de 1980, consultar Le Grand e Bartlett (1993); conferir ainda Estevão (1998a, p. 40-54 e 78-89) e Afonso (1998, p. 155-161). 
de que dispomos sugerem que, pelo menos até 1998, embora se tenham criado algumas das condições características do, e se tenham registado fenómenos associáveis ao, funcionamento de um quase-mercado, ${ }^{9}$ outros se lhe agregaram de natureza menos clara: a ambiguidade dos projectos e do processo envolvidos no lançamento e desenvolvimento desse subsistema, em que se inclui o compromisso do Estado com a fundação de cada escola profissional e com a sustentação desse sector de ensino, a ausência inicial de uma procura consolidada, uma certa fragilidade institucional das próprias escolas terão contribuído para, numa primeira fase do seu funcionamento, complexificar e/ou obscurecer os contornos desse quase-mercado em educação.

Gostaríamos de sugerir que o novo regime de criação, organização e funcionamento de escolas e cursos profissionais no âmbito do ensino não-superior estabelecido através do decreto-lei $n^{\circ}$ 4/98 de 8 de janeiro contribuiu para clarificar a situação: o re-

${ }^{9}$ Por exemplo - ainda que não estejam disponíveis dados e estudos que permitam avaliar até que ponto e em que sentidos a intensidade de tais fenómenos chega a marcar a configuração e o funcionamento desse subsistema e o campo do ensino/formação de nível secundário -, são significativas formas de actuação adoptadas que indiciam a concorrência entre as entidades que produzem o serviço educativo, quer para atrair consumidores, quer para aceder a contratos públicos de fornecimento do mesmo: a oferta de cursos mais orientados para suscitar a adesão dos estudantes do que para "responder" a necessidades percepcionadas da economia, a promoção dos cursos e das escolas profissionais junto dos seus públicos potenciais (associada a uma perspectiva que define o campo da educação/formação de nível secundário como constituído por instituições que concorrem para atrair um mesmo contingente de jovens), mas também, como constatámos em duas escolas estudadas, a selecção, mais ou menos apurada, dos candidatos aos cursos profissionais de modo a reter aqueles que parecem reunir condições para facilitar e favorecer o desempenho desejado das instituições (quer em termos de progressão nas aprendizagens e percentagem de diplomados no tempo previsto, quer em termos de colocações no mercado de emprego). gime de criação através de contrato-programa, entre promotores e o Ministério da Educação, é substituído pelo regime de liberdade de criação sujeito a autorização prévia de funcionamento pelo Estado: a figura dos promotores é substituída pela de entidades proprietárias, enquanto a participação do Estado passa pelo estabelecimento de contratos-programa com as escolas que possibilitam a frequência, por parte dos alunos, dos cursos profissionais (publicamente comparticipados) em condições idênticas àquelas em que frequentariam o ensino secundário (artigos 19 e 20 do decreto-lei $n^{\circ}$ 4/98). As escolas profissionais deixam, portanto, de ter por base o partenariado (quer com o Estado, quer entre promotores), e o seu financiamento público é condicionado pela celebração de contratos-programa plurianuais, de duração limitada, relativos a cursos e número de alunos específicos; dessa forma, sem ambiguidades, o Estado passou a, em certas condições, adquirir determinados serviços educativos proporcionados pelas escolas, declinando, assim, o tácito compromisso com a sustentação financeira desse subsistema quase exclusivamente privado (o que pode não ter alterado a situação de, agora enquanto "cliente", permanecer como o seu principal financiador). Nesse sentido, terão sido reforçadas as condições que, conforme argumentámos, potenciavam já o estabelecimento de um quase-mercado nesse sector do sistema de ensino - fortemente regulado pelo Estado, com instituições autónomas competindo por contratos de fornecimento de serviços educativos, enquanto a relação com os destinatários/consumidores combina a aquisição directa do serviço (através de propinas) com a mediação do Estado em representação daqueles.

Deve ser notado que essa evolução alterou significativamente o quadro da governação desse subsistema. Se, nesse momento, o seu financiamento é ainda predominantemente suportado por entidades públicas (a União Europeia e o Estado português), essa sustentação decorre de contratos de aquisição de serviços fornecidos pelas escolas. Nesse sentido, o financiamento provém agora dos beneficiários, directamente através de propinas, ou indirectamente pela 
via de um contrato com o Estado em representação dos estudantes. Assim, as formas institucionais de coordenação social dominantes nessa área da governação serão actualmente o mercado e o quase-mercado (ver Quadro 2).

\section{Quadro 2}

A governação das escolas profissionais após 1998

\begin{tabular}{|c|c|c|}
\hline \multirow{2}{*}{ Financiamento } & Governação & $\begin{array}{c}\text { Formas intitucionais } \\
\text { de coordenação social }\end{array}$ \\
\hline & $\begin{array}{c}\text { entidades proprietárias } \\
\text { beneficiários/consumidores } \\
\text { (directamente ou o Estado } \\
\text { em sua representação) }\end{array}$ & $\begin{array}{c}\text { Terceiro Sector } \\
\text { Quase-mercado }\end{array}$ \\
\hline \multirow{2}{*}{ Fornecimento } & Mercado \\
\hline \multirow{2}{*}{ Regulação } & $\begin{array}{c}\text { Escolas } \\
\text { do sistema educativo) }\end{array}$ & $\begin{array}{c}\text { Terceiro Sector? } \\
\text { Escolas (órgãos de }\end{array}$ \\
& direcção e gestão) & Terceiro Sector \\
\hline
\end{tabular}

Em contrapartida, as propostas conhecidas para o financiamento, após a conclusão do $3^{\circ}$ Quadro Comunitário de Apoio da União Europeia em 2006, e que foram experimentadas já no ano lectivo 2003/ 2004 nas escolas profissionais da região de Lisboa e Vale do Tejo, passam pela atribuição, pelo Estado, de bolsas aos estudantes, seleccionados com base no aproveitamento obtido no nono ano, que serão pagas às escolas. Não sendo ainda conhecidas com a necessária precisão as condições em que esse novo sistema de financiamento decorrerá e, muito menos, as suas consequências, não é possível analisar as mudanças introduzidas em termos do serviço educativo que, de acordo com essa nova modalidade, será proporcionado. No entanto, parecem acumular-se as indicações de que a institucionalização desse quasemercado será consolidada, agora sob novos moldes; desse modo, poderemos ainda testemunhar o reforço de mecanismos de mercado, já que é susceptível de vir a adquirir um maior significado a participação do financiamento privado pelos próprios estudantes, através de propinas.

\section{Considerações finais}

A criação e desenvolvimento do subsistema de escolas profissionais constituiu uma inovação sociopolítica que afirmou a tendência, a vários títulos notável, de estabelecimento de novas modalidades de provisão da educação que incluem como vectores integrantes a autonomia, a privatização, a regulação estatal, e ainda formas e intensidades variadas de mobilização social. No caso vertente, aquela medida política parece ter ensaiado um conjunto de formas inéditas com relevo para uma área que tem vindo a ser alvo de sucessivas e profundas alterações: a administração do sistema educativo. ${ }^{10}$ Assim, no que toca à governação (financiamento, fornecimento e regulação) dos serviços educativos, a criação do subsistema de escolas profissionais parece representar uma tentativa de mudança congruente com a rearticulação de novos papéis do Estado na regulação social. Tratarse-ia da criação de combinações institucionais que permitissem a distribuição e transferência de algumas competências e responsabilidades do Estado para operadores situados quer no domínio do mercado, quer do designado terceiro sector.

${ }^{10}$ Desde há quinze anos, em Portugal procedeu-se a um ensaio de reforma, entre 1991-1997, e, a partir de 1998, à implementação de um novo modelo de administração do sistema educativo e das escolas, bem como a múltiplas e profundas alterações em torno da constituição de unidades de gestão designadas como agrupamentos de escolas. Está neste momento em fase de não-promulgação pelo presidente da República - após aprovação pelo Parlamento apenas com os votos dos partidos da maioria de direita no governo, Partido Popular (PP) e Partido Social Democrata (PSD) - uma lei de bases da educação que prevê a introdução de vastas mudanças naquela área de funcionamento do sistema de ensino português. Para um conhecimento mais amplo do processo em curso desde há cerca de vinte anos, consultar Lima (1998, 2000), Lima e Afonso (2002). 
A reconstituição do papel do Estado na provisão do bem-estar social tem vindo a passar, por um lado, pela instabilização e rarefacção de fronteiras entre o domínio público, estatal e não-estatal, e o domínio privado, associável ao mercado e/ou ao terceiro sector; e, por outro lado, pela retenção da (quase) exclusividade de algumas dimensões da governação (para as escolas profissionais, num primeiro momento, o financiamento e a regulação) e a retirada (quase) completa de outros domínios (o fornecimento).

As consequências dessa retirada, no caso das escolas profissionais, apontam para uma divisão do trabalho educativo, com a criação de um nível de responsabilidade intermédio, entre a autoridade política, que avaliza, regula e controla (e financia) o serviço, e os seus produtores e beneficiários. Configura-se, desse modo, a criação de condições para a individualização da relação de trabalho entre os produtores do serviço educativo (professores e funcionários) e a entidade que o fornece (a escola), e para a potencial mercadorização da relação entre os seus beneficiários e a educação. Nesse sentido, a delegação da prestação de serviços através de contratos-programa ganha relevo como instrumento, progressivamente utilizado de forma mais intensiva nos últimos anos, de reestruturação das relações entre os cidadãos, a educação e o Estado.

A ambiguidade da política então lançada em 1989 aponta ainda para uma (intencionada, embora ainda não concretizada em sentido pleno) retirada do Estado do domínio do financiamento, podendo virtualmente gerar modalidades de mercadorização directa ou indirecta do serviço educativo, institucionalizando o princípio usador-pagador aplicável quer aos alunos beneficiários, quer às empresas (e economia local), consumidores finais. Foram, no entanto, criadas as condições para a gestação de um quase-mercado em educação, cujo desenvolvimento foi, num primeiro momento, retardado, sendo retomado após as alterações introduzidas em 1998.

Na primeira fase de funcionamento do subsistema, a mobilização de promotores como entidades patrocinadoras, legalmente responsáveis pela escola, a quem foi outorgada autonomia, permitiu ainda institucionalizar novas formas de distribuição de poderes na administração da educação, alternativas àquelas que vigoravam nas escolas públicas. Os professores foram remetidos para a gestão pedagógica e curricular, os alunos e funcionários ficaram reduzidos à categoria de figurantes mudos no que toca à participação substantiva nos órgãos da instituição, cuja direcção e gestão se concentrou nos promotores e seus representantes, e/ou nos responsáveis por eles escolhidos e designados.

A definição de configurações institucionais e de modalidades de administração da educação inéditas que viabilizam uma nova distribuição de responsabilidades, competências e âmbitos de actuação, com base na autonomia das instituições e em diversos tipos de participação e mobilização dos actores sociais e da "comunidade", e que podem também criar condições susceptíveis de favorecer a emergência de quase-mercados e/ou de outras formas de liberalização em educação - traçam os contornos de novos papéis assumidos pelo Estado na provisão da educação (e do bem-estar social) em que, permanecendo no centro da regulação e do controlo do sistema, não é já o único e poderá até deixar de ser o principal protagonista. Como defendemos já em outros trabalhos, os problemas confrontados pelo Estado português - em que a prioridade à competitividade nacional e ao processo de acumulação se conjugou com pressões sociais contraditórias relacionadas com a expansão dos serviços educativos - criaram as condições para a gestação de uma inovação política em que se combinam, de modo específico, as formas de actuação como Estado de competição e como Estado articulador (Antunes, 2001). A modalidade de provisão de bem-estar assim estabelecida é marcada pela tendência para ampliar o domínio do privado como locus de promoção do bem comum; neste processo, é o próprio modelo de provisão de serviços educativos que é alterado. A dinâmica gerada é, no entanto, suficientemente heterogénea e ambivalente para sugerir que formas inovadoras de promoção da coesão com justiça social podem também ter sido experimentadas. 
Por outro lado, a distribuição de responsabilidades e competências no campo do bem-estar social, apelando à intervenção de outros actores e definindo esferas de acção (delegadas), revela o carácter ambíguo dos processos em curso - quer a individualização (associada ou não à mercadorização) das relações sociais, quer o descompromisso do Estado diante de algumas tarefas (e alguns grupos sociais), quer a abertura de novos espaços e modalidades de acção colectiva se apresentam como desenvolvimentos possíveis, cuja combinação e efeitos se revelam distintos quanto ao seu potencial para promover a coesão com justiça social.

FÁTIMA ANTUNES, doutora em educação pela Universidade do Minho, é professora do departamento de sociologia da educação e administração educacional do Instituto de Educação e Psicologia da mesma instituição. Investigadora efetiva do Centro de Investigação em Educação do Instituto de Educação e Psicologia da Universidade do Minho e investigadora associada do Centro de Investigação e Intervenção em Educação da Faculdade de Psicologia e Ciências da Educação da Universidade do Porto. Principais publicações: Políticas educativas nacionais $e$ globalização. Novas instituições e processos educativos. O subsistema de escolas profissionais em Portugal (1987/1998) (Braga: Universidade do Minho, 2004); Os locais das escolas profissionais: novos papéis para o estado e a europeização das políticas educativas (In: STOER, S. R., CORTESÃO, L. e CORREIA, J. A. (orgs.). Transnacionalização da educação: da crise da educação à "educação" da crise. Porto: Afrontamento, 2001, p. 163208); Novas instituições e processos educativos: a reforma portuguesa do ensino secundário no contexto comunitário (19881996) (In: J. A. Pacheco (org.), Políticas educativas: o neoliberalismo em educação. Porto: Porto Editora, 2000, p. 109-134); Novas diferenciações e formas de governação em educação: o processo de criação de escolas profissionais em Portugal (Revista Brasileira de Política e Administração da Educação, Porto Alegre, v. 16, nº 1, 2000, p. 31-45). Projetos de investigação em curso: "Políticas educativas nacionais, europeização e globalização: a reconfiguração da educação" e "Excelência académica e escola para todos" (projecto colectivo, coordenado por Luiza Cortesão e por Stephen Stoer, promovido pelo Instituto Paulo Freire-Portugal, inscrito no Centro de Investigação e Interven- ção em Educação da Faculdade de Psicologia e Ciências da Educação da Universidade do Porto e financiado pela Fundação Calouste Gulbenkian).E-mail: fantunes@iep.uminho.pt

\section{Referências bibliográficas}

AFONSO, Almerindo J., (1998). Políticas educativas e avaliação educacional: para uma análise sociológica da reforma educativa em Portugal (1985-1995). Braga: Universidade do Minho.

, (2001). A redefinição do papel do Estado e as políticas educativas: elementos para pensar a transição. Sociologia: problemas e práticas, Lisboa, $\mathrm{n}^{\circ} 37$, p. 33-48.

AGLIETTA, Michel, (1997). Régulation et crises du capitalisme. Paris: Éditions Odile Jacob.

ANTUNES, Fátima, (1998). Políticas educativas para Portugal, anos 80/90: o debate acerca do ensino profissional na escola pública. Lisboa: Instituto de Inovação Educacional.

, (2000). Novas instituições e processos educativos: a reforma portuguesa do ensino secundário no contexto comunitário (1988-1996). In: PACHECO, J. A. (org.). Políticas educativas: o neoliberalismo em educação. Porto: Porto Editora, p. 109-134.

(2001). Os locais das escolas profissionais: novos papéis para o Estado e a europeização das políticas educativas. In: STOER, S. R., CORTESÃO, L., CORREIA, J. A. (orgs.). Transnacionalização da educação: da crise da educação à "educação" da crise. Porto: Afrontamento, p. 163-208. , (2004). Políticas educativas nacionais e globalização: novas instituições e processos educativos: o subsistema de escolas profissionais em Portugal (1987-1998). Braga: Universidade do Minho.

ALVES, José Matias, (1996). Modos de organização, direcção e gestão das escolas profissionais: um estudo de quatro situações. Porto: Porto Editora.

AZEVEDO, Joaquim, (1991). Educação tecnológica nos anos noventa. Rio Tinto: Edições Asa.

BOYER, Robert, (1987). La théorie de la régulation: une analyse critique. Paris: La Découverte.

, (1994). As alternativas ao fordismo dos anos 80 ao século XXI. In: BENKO, G., LIPIETZ, A. (orgs.). As regiões ganhadoras: distritos e redes, os novos paradigmas da geografia económica. Oeiras: Celta, p. 121-142. 
CASTELLS, Manuel, (1997). The information age: economy, society and culture - v. 2: The power of identity. Oxford: Blackwell Publishers.

, (1998). The information age: economy, society and culture - v. 3: End of millennium. Oxford: Blackwell Publishers.

CATANI, Afrânio M., OLIVEIRA, Romualdo P., (orgs.) (2000). Reformas educacionais em Portugal e no Brasil. Belo Horizonte: Autêntica.

CERNY, Philip G., (1990). The changing archicteture of politics: structure, agency and the future of the State. Londres: Sage.

CORREIO PEDAGÓGICO, (1988). Vem aí nova alternativa após o $9^{\circ}$ ano: escolas profissionais serão alfobre de quadros intermédios. Correio Pedagógico, Porto, nº 25, p. 4.

DALE, Roger, (1994). Applied education politics or political sociology of education? In: HALPIN, D., TROYNA, B. (orgs.). Researching education policy: ethical and methodological issues. Londres: Falmer Press, p. 31-41.

, (1997). The State and the governance of education: an analysis of the restructuring of the State-education relationship. In: HALSEY, A. H., LAUDER, H., BROWN, Ph., WELLS, A. S. (orgs.). Education, culture, economy and society. Nova Iorque: Oxford University Press, p. 273-282.

, (2000). Globalization and education: demonstrating a "common world educational culture" or locating a "globally structured educational agenda"? Educational Theory, Illinois, v. $50, n^{\circ} 4$, p. $427-448$.

ESTEVÃO, Carlos A. V., (1998a). Redescobrir a escola privada portuguesa como organização: na fronteira da sua complexidade organizacional. Braga: Universidade do Minho.

, (1998b). A privatização da qualidade na educação e as suas privações. Sociologia: problemas e práticas, Lisboa, $\mathrm{n}^{\circ} 27$, p. $117-127$.

GIDDENS, Anthony, (2000). O mundo na era da globalização. Lisboa: Presença.

LE GRAND, J., BARTLETT, W., (orgs.) (1993). Quasi markets and social policy. Londres: The Macmillan Press.
LIMA, Licínio C., (1992). A escola como organização e a participação na organização escolar. Braga: Universidade do Minho.

, (1998). A administração do sistema educativo e das escolas (1986/1996). In: Colecção. A evolução do sistema educativo e o PRODEP. Lisboa: Ministério da Educação/Departamento de Avaliação, Prospectiva e Planeamento, Estudos Temáticos, v. 1, p. 15-96.

(2000). Administração escolar em Portugal: da revolução, da reforma e das decisões políticas pós-reformistas. In: CATANI, A. M., OLIVEIRA, R. P. (orgs.). Reformas educacionais em Portugal e no Brasil. Belo Horizonte: Autêntica, p. 41-76.

LIMA, Licínio C., AFONSO, Almerindo J., (2002). Reformas da educação pública: democratização, modernização, neoliberalismo. Porto: Afrontamento.

SANTOS, Boaventura de S., (1998). Reinventar a democracia. Lisboa: Fundação Mário Soares/ Gradiva. ,(1999). A reinvenção solidária e participativa do Estado. Coimbra: Centro de Estudos Sociais (Oficina do CES n $\left.{ }^{\circ} 134\right)$. , (2001). Os processos de globalização. In: SANTOS, B. S. (org.). Globalização: fatalidade ou utopia? Porto: Afrontamento, p. 31-106.

SILVA, Júlio M., SILVA, Augusto S., FONSECA, José M. P. da, (1997). Avaliação do sistema de escolas profissionais. Lisboa: Ministério da Educação.

\section{Legislação referenciada}

Decreto-lei n ${ }^{\circ}$ 26/89 de 21 de janeiro. Diário da República n $^{\circ} 18$, I série.

Decreto-lei nº 70/93 de 10 de março. Diário da República nº 58, I série - A.

Decreto-lei $n^{\circ} 4 / 98$ de 8 de janeiro. Diário da República ${ }^{\circ}$ 6, I série - A.

Recebido em novembro de 2004 Aprovado em janeiro de 2005 


\section{Resumos/Abstracts}

\section{Fátima Antunes}

\section{Reformas do Estado e da educação: o caso das escolas profissionais em Portugal}

O ensaio de novas modalidades de provisão da educação teve em Portugal uma ilustração particularmente rica e complexa, protagonizada pela criação e desenvolvimento do subsistema de escolas profissionais. As características dessa inovação sociopolítica condensaram alguns dos principais vetores que posteriormente assumiram uma importância incontornável nas transformações sofridas pela administração do sistema de ensino, bem como em algumas das mais expressivas alterações verificadas em diversas áreas das políticas de bem-estar social; o subsistema de escolas profissionais organizou-se na sua gênese em torno da autonomia, privatização, mobilização social e regulação estatal. Estas constituíram tendências cujos desenvolvimento e articulação se encontram em diversas formas com algumas das mudanças produzidas, ao longo das últimas décadas, e desde há alguns anos com uma acuidade particular, nos serviços públicos em Portugal, incluindo a educação.

Palavras-chave: reforma do Estado; governação da educação; políticas sociais; quase-mercados em educação

\section{Reforms of education and of the State: the case of vocational schools in Portugal}

The creation of the vocational school subsystem in Portugal constitutes a particularly rich and complex illustration of the testing of new modalities of provision of education. The features of this socio-political innovation condensed some of the main vectors that later assumed great importance in the transformations undergone by the management of the education system in general. Moreover, the same is true in respect of the changes verified by several areas of social welfare policy; the vocational school subsystem was organised from the beginning on the basis of autonomy, privatisation, social mobilisation and state regulation. These constitute crucial political tendencies whose development and articulation can be found in different forms in some of the changes produced in public services, including education, during the last decades, and with particular force in recent years.

Key-words: Reform of the State; education governance; social policies; quasi-markets in education 